\title{
EINEND, VERNETZEND, VORAUSSCHAUEND, FÖRDERND
}

\section{von Wolfgang Mayer}

Ich glaube, zu wissen, dass der plötzliche Tod Bruno Bauers für viele einen schmerzlichen (teilweise zutiefst persönlichen) Verlust bedeutet. Wir alle sind uns bewusst, dass er einen Krater im österreichischen Bibliothekswesen hinterlässt, an dem wir uns lange abarbeiten werden.

Brunos Bedeutung als herausragender Bibliothekar, verlässlicher Verantwortungsträger und (auffällig oft und zutreffend vermerkt) aktiver und erfolgreicher Netzwerker wurde schon in den ersten Würdigungen nach seinem Ableben vielerorts betont. Ich bin mir sicher, es werden noch viele weitere derartige Texte von berufenen Kolleg*innen folgen. Es ist aber auch die Zeit wert, zu überlegen, was ihn zu diesen (im besten Sinne des Wortes) „Funktionen“ befähigt hat.

Erstens die Überzeugung, immer das Einende, die Zusammenarbeit, das Zusammenspiel unterschiedlicher Fähigkeiten über das Trennende, die Konkurrenz zu stellen. Nicht sich selbst und den eigenen Erfolg ins Rampenlicht zu stellen sondern die gemeinsame Bemühung ... sowie gemeinsame Erfolge auch nach innen und außen zu kommunizieren. In seinem ORCiD-Account (https://orcid.org/0000-0002-4729-331X) sind 195 Publikationen gelistet, der überwiegende Teil davon diesen Zielen entsprungen.

Zweitens das „Netzwerken“ niemals als Adabei zu betreiben oder damit Tratsch und Klatsch voranzutreiben, sondern um Entwicklungen frühzeitig aufzuschnappen, Menschen und ihre Talente kennenzulernen und gegebenenfalls auch zusammenzubringen. Vielleicht war er dabei nie/selten völlig privat, ganz sicher aber zutiefst menschlich und sympathisch.

Drittens der Antrieb, immer ein vorwärts gerichtetes und zukunftsfähiges Bibliothekswesen mitzuentwickeln. Open Access, Big Deals, Zertifizierungen und Leistungsstandards, Peer Review auch bei Bibliothekspublikationen, die Liste ließe sich beliebig fortsetzen. Und trotzdem das Bewusstsein dafür, die Geschichte nicht zurückzulassen und auch Arbeit in deren Analyse und Aufarbeitung zu investieren und Lehren daraus zu ziehen („Vertrieben 1938“).

Viertens ein sicherer und unbestechlicher Blick für Talente und Fähigkeiten, unbeeinflusst von Geschlecht, Herkunft, Alter, Auftreten, und der Wille und oft genug die Zähigkeit, die Träger*innen dieser Talente einzubinden und zu fördern. 
Das Bewusstsein über den Wert solcher Überzeugungen und Leistungen sollte fortwährend wachgehalten werden. Dazu helfen Identifikationspersonen wie Bruno im Besonderen. In unserer Erinnerung, der seiner Zeitgenoss*innen wird er in jedem Fall lebendig bleiben.

Wolfgang Mayer

Universität Wien, Bibliotheks- und Archivwesen

E-Mail:wolf.mayer@univie.ac.at

DOI: https://doi.org/10.31263/voebm.v73i3-4.5341

(c) Wolfgang Mayer

Dieses Werk ist - exkl. einzelner Logos und Abbildungen - lizenziert unter einer Creative-Commons-Lizenz Namensnennung 4.0 International-Lizenz 